\title{
Facilitating Access to a COVID-19 Vaccine through Global Health Law
}

Global Health Law

\author{
Lawrence O. Gostin, \\ Safura Abdool Karim, \\ and Benjamin Mason Meier
}

Threatening the entire world, the burden of the COVID-19 pandemic has continued to grow, with devastating effects on human health, social connections, and economic livelihoods. These crushing burdens are likely to increase dramatically as the pandemic continues its relentless march across the globe. Some governments have taken steps to mitigate the worst impacts of this threat through aggressive public health interventions - including diagnostic testing, contact tracing, widespread masking, and physical distancing - but with the pandemic expected to inflict unprecedented human suffering in the months ahead, it has become clear that only a vaccine will be able to contain the COVID-19 threat.

There has not been a more soughtafter medical resource in our lifetimes than a safe and effective COVID-19 vaccine, and given this existential threat, vaccine candidates will move swiftly into clinical trials in the coming months. While vaccine development holds great promise, the discovery phase is only the first step. Clinical trials may well demonstrate that one or more vaccine candidates is safe and effective, yet those vaccines must still be approved by regulatory authorities, manufactured and distributed to scale, and made affordable for all. Depending on how these issues are resolved, a prospective vaccine could heal the rifts of a bitterly divided world, or it could exacerbate them if countries hoard a necessary vaccines and undermine equitable access.

This column explores the global health law reforms necessary to progressively realize universal access to a future COVID-19 vaccine. We begin by explaining the importance of global health law in the distribution of essential vaccines as a determinant of public health. The column then turns to examine the human rights foundations of global health law, conceptualizing vaccination access as a universal human right. We find that it will be crucial to develop legal commitments to ensure vaccine access prior to a scientific breakthrough, analyzing the legal barriers that impede global access and the global health law reforms necessary to facilitate global solidarity.

\section{Vaccination Access through Global Governance}

As governments have found themselves constrained in national efforts to mitigate the pandemic, it appears almost certain that COVID-19 will not be controlled globally without the development of a vaccine. An effective vaccine will be essential to limit the spread of the SARS-CoV-2 virus, prevent it from reoccurring, and bring about the eventual containment of the COVID-19 pandemic. Without lasting protection from infection and population-level immunity, the world will face higher transmission, repeated outbreaks, and unnecessary deaths. ${ }^{1}$ Yet, these immunization benefits can only be realized if there is sufficient

Lawrence O. Gostin, J.D., LL.D. (Hon.), is University Professor at Georgetown University and the Founding Linda D. E' Timothy J. O'Neill Professor of Global Health Law at Georgetown University Law Center and Director of the World Health Organization Center on National and Global Health Law. Safura Abdool Karim, LL.B., LL.M., is a senior researcher at the SAMRC Centre for Health Economics and Decision Science - PRICELESS SA at the Wits School of Public Health. Benjamin Mason Meier, J.D., LL.M., Ph.D., is an Associate Professor of Global Health Policy at the University of North Carolina at Chapel Hill and a Scholar at the O'Neill Institute for National and Global Health Law. 
access across all countries. If any country or region is left out, global protection remains at considerable risk.

Ensuring worldwide vaccination coverage will require global governance. An effective vaccine should be seen as a global public good, with benefits shared by all nations but requiring global cooperation to guarantee its benefits. ${ }^{2}$ No country should hoard it. No corporation should profit from it. And no institution or individual should own intellectual property rights. Despite the rise of "vaccine nationalism," no health law. Even if several vaccines are approved in the coming year, few low- and middle-income countries (LMICs) will have the capacity to produce vaccines without affordable access to global supply chains. ${ }^{4}$ Determining how to distribute a vaccine within and across countries is a global concern that cannot be decided by a single nation or pharmaceutical corporation. ${ }^{5}$ With so much global competition, no government can be sure its scientists or pharmaceutical companies will be "first and best." It is now, before we know who will prevail

\section{While vaccine development holds great promise, the discovery phase is only the first step. Clinical trials may well demonstrate that one or more vaccine candidates is safe and effective, yet those vaccines must still be approved by regulatory authorities, manufactured and distributed to scale, and made affordable for all. Depending on how these issues are resolved, a prospective vaccine could heal the rifts of a bitterly divided world, or it could exacerbate them if countries hoard necessary vaccines and undermine equitable access.}

country acting alone can assure success. ${ }^{3}$ Collaboration and coordination are needed for every stage in vaccine development and implementation: scientific cooperation in discovery and clinical trials, global manufacturing and distribution in sufficient quantities, and equitable allocation worldwide. We are unlikely ever to eradicate SARS-CoV-2, but the World Health Organization (WHO) vaccination campaign that eradicated smallpox demonstrates the need for international cooperation, bringing nations together to accomplish what none can do alone.

Effective governance for vaccine discovery, production, and distribution requires a coalition of state and non-state actors through global in this vaccine competition, that we must plan for equity. ${ }^{6}$ Global health law reforms are necessary to assure that a prospective vaccine is distributed fairly based upon global norms, realizing vaccination as a universal right.

\section{Vaccination as a Human Right}

Human rights law provides an international legal foundation for the progressive realization of vaccine access. COVID-19 not only endangers health and longevity, but does so inequitably - burdening the poor, the sick, the disadvantaged, and the marginalized. Recognizing the equal dignity of all persons, human rights law requires equitable access to essential vaccines for disease prevention and health promotion.7 A growing anti-vaccination movement is already mobilizing under "rights" discourse to oppose a prospective COVID-19 vaccine; ${ }^{8}$ however, this co-optation of human rights rhetoric does not obviate human rights obligations to ensure access to essential medicines. In realizing the highest attainable standard of health through vaccination, human rights law provides an international obligation to progressively realize the prevention, treatment, and control of prevalent diseases.

Access to an essential lifesaving vaccine is a core human rights obligation. Immunization is science's best prevention tool and remains a quintessentially important element of the right to the highest attainable standard of health. ${ }^{9}$ The United Nations Special Rapporteur on the right to health concluded that states are obligated to "do all they reasonably can to make sure that existing medicines are available in sufficient quantities."10 The widespread provision of a COVID-19 vaccination also finds support under the human right to the benefits of scientific progress, requiring that states provide resources for the distribution of scientific progress, remove discriminatory barriers, and ensure access to the "most advanced, up-to-date, and verifiable science available."11 In realizing these rights, a COVID-19 vaccination, similar to life saving antiretrovirals for HIV, will almost certainly be classified by WHO as an "essential medicine," raising national and international obligations to ensure access. ${ }^{12}$

States bear international legal obligations to progressively realize universal access to vaccines, demanding that national resources and international assistance move "as expeditiously and effectively as possible towards the full realization" of rights. ${ }^{13}$ To implement human rights to a prospective COVID-19 vaccine, states must ensure that any safe and effective vaccination is:

- Available - requiring that states provide sufficient quantities of vaccine goods and services and highlighting the importance of 
widespread production and rapid distribution.

- Accessible - requiring that the distribution of vaccines accounts for obstacles faced by vulnerable and marginalized populations, ensuring a vaccine that is affordable, within safe physical reach, and delivered with all necessary information.

- Acceptable - requiring that this essential intervention be respectful of medical ethics such as informed consent and be designed to account for distinct cultural considerations across populations.

- OfSufficient Quality - requiring that the vaccine be "scientifically and medically appropriate and of good quality," avoiding counterfeit and sub-standard vaccines and employing skilled personal and approved equipment. ${ }^{14}$

The implementation of human rights to realize access to a COVID-19 vaccine will require the development of new forms of global governance through law.

\section{Global Governance through Global Health Law}

The reform of global health law to ensure universal access to a COVID19 vaccine will require: facilitating funding and benefit sharing, easing intellectual property protections, and harmonizing national vaccine regulations.

\section{Funding and Benefit Sharing}

Equitable access to a COVID-19 vaccine will hinge on its widespread production, global supply chains, accessibility, acceptability, and affordability. Global governance could lower vaccine prices, ramp up industry production, and ensure global distribution, but existing Global Public/ Private Partnerships (GPPPs) lack the legal accountability necessary to ensure benefit sharing. Gavi, the Vaccine Alliance was the first GPPP to use advanced market commitments and bulk purchasing to secure lower vaccine prices. ${ }^{15}$ To accelerate the development of new vaccines against emerging infectious diseases, the Coalition for Epidemic Preparedness Innovations (CEPI) was launched to facilitate access to new vaccines during outbreaks. With both Gavi and CEPI repurposing to facilitate access to a future COVID-19 vaccine, WHO has joined them in establishing a new GPPP, the COVID-19 Vaccine Global Access (COVAX) Facility; however, even with support from large donor countries and foundations, these GPPPs lack the legitimacy and funding with which to coordinate nationalist governments and pharmaceutical companies. ${ }^{16}$

There is a need to create a universal global health law mechanism to ensure equitable benefit sharing, particularly for LMICs that have limited access to new health technologies. The WHO Pandemic Influenza Preparedness (PIP) Framework is the only existing global mechanism to obligate governments to share biological samples and genetic sequencing data needed to promote research. The PIP Framework also promotes equitable sharing of the benefits of research. That Framework, however, only applies to pandemic influenza pathogens. ${ }^{17}$ Although there are a number of GPPPs to promote knowledge-sharing in COVID-19 research, ${ }^{18}$ a binding framework for equitable sharing will be needed to prevent states from hoarding a prospective vaccine. New benefit sharing agreements in global governance can ensure that states act for the common good, limit the commercialization of publicly funded research, and support equitable COVID-19 vaccine access.

\section{Intellectual Property}

The tensions between intellectual property and public health could also impede global access to a prospective COVID-19 vaccine. Under World Trade Organization (WTO) governance, the Agreement on Trade-Related Aspects of Intellectual Property Rights (TRIPS) allows for the global enforcement of intellectual property (IP) rights. The TRIPS agreement thus allows developers of vaccines to enforce patent protections to monopolize production and maximize profit. ${ }^{19}$ As TRIPS made life-saving medicines unaffordable in LMICs, the 2001 WTO Doha Declaration sought to create "flexibilities" to limit IP protections to protect public health. ${ }^{20}$ However, these measures to support affordable medicines cannot easily be translated to vaccines. Compulsory licensing can remove IP barriers for the production of generic medicines, but in the context of vaccines, these IP flexibilities cannot address the shortage of infrastructure, capacity, technical knowledge, and regulatory recognition necessary for generic vaccines. ${ }^{21}$

Making vaccines affordable requires increasing vaccine manufacturing capacity in LMIC and providing new legal mechanisms to share technical production processes. Understanding protections on production processes - not only final products - will be crucial to making a COVID-19 vaccine affordable. UNITAID and the Medicines Patent Pool have successfully negotiated global patent clearing houses to support the production of affordable drugs. ${ }^{22}$ The COVID-19 Technology Access Pool (C-TAP) recognizes the complexity of making vaccines affordable and seeks to facilitate the sharing of data, IP, and knowledge while compensating the patent holder. ${ }^{23} \mathrm{C}$-TAP could play a critical role in making compulsory licenses feasible for a COVID-19, vaccine but this voluntary system ${ }^{24}$ will require stronger enforcement through global health law to ensure widespread participation of public and private actors and alignment of international trade law with global health imperatives.

\section{Vaccine Regulation}

Finally, where the safety and effectiveness of a COVID-19 vaccine will require approval in every country, creating a patchwork of national regulatory obstacles, global health law is necessary to harmonize and expedite national vaccine regulations. In many countries, national approval processes may be unduly burdensome - and at times unnecessary if a stringent regulatory authority (like the US FDA or the European Medicines Agency) has already approved the 
technology. ${ }^{25}$ Simultaneously, a lack of regulatory capacity in some countries can delay rollout or allow falsified or substandard products to enter the market. ${ }^{26}$ Despite WHO efforts to harmonize national approval processes, national governments have differing regulatory capacities to evaluate and approve new drugs, and vaccine approval processes have remained slower than necessary in many countries. ${ }^{27}$

Against this diverse national regu- cines, global health law can support efficient processes to regulate and approve a safe and effective COVID19 vaccine.

\section{Overcoming the World's Greatest Challenge}

The COVID-19 response has proven to be the greatest challenge the world has faced in generations, and it can be contained only if nations are willing and able to work together. Yet, despite an imperative for collective

\section{The COVID-19 response has proven to be} the greatest challenge the world has faced in generations, and it can be contained only if nations are willing and able to work together. Yet, despite an imperative for collective action, governments have scrambled to establish nationalist legal agreements to hoard prospective vaccines while dividing the world in ways that will prolong the pandemic threat. Although the barriers to global health coordination and universal vaccine access remain complex, global health law can support global solidarity in facing this common threat, reaching agreements now to secure equitable access to a hopeful new vaccine.

latory landscape, global health law can support the regulation of new vaccines in an efficient and effective manner. The WHO Pre-Qualification Process $^{28}$ (PQP) can serve in place of national regulations and streamline regulatory approvals for a COVID19 vaccine - provided that states introduce laws recognizing the PQP. WHO has additionally recommended the establishment of National Immunization Technical Advisory Groups (NITAG) to provide evidence-based advice on vaccines and immunization. ${ }^{29}$ NITAGs can support regulations for the financing and delivery of prospective vaccines and prioritize public health and health equity in vaccine access. By strengthening national capacity to approve vac- action, governments have scrambled to establish nationalist legal agreements to hoard prospective vaccines while dividing the world in ways that will prolong the pandemic threat. Although the barriers to global health coordination and universal vaccine access remain complex, global health law can support global solidarity in facing this common threat, reaching agreements now to secure equitable access to a hopeful new vaccine.

\section{Note}

The authors have no conflicts to disclose.

\section{Acknowledgements}

The authors are grateful to Victoria Matus, Sonam Jyoti Shah, and Anisha Khanna for their thoughtful research assistance in framing crucial debates in vaccination policy.
References

1. B.S. Graham, "Rapid COVID-19 Vaccine Development" Science 368, no. 6494 (2020): 945-946.

2. S. Moon et al., "Global Public Goods For Health: Weaknesses and Opportunities in the Global Health System,' Health, Economics, Policy and Law 12, no. 2 (2017): 195-205.

3. M. Cueto et al., The World Health Organization: A History (Cambridge University Press, 2019).

4. G. Makenga et al., "Vaccine Production in Africa: A Feasible Business Model for Capacity Building and Sustainable Vaccine Introduction," Frontiers in Public Health (2019), available at <https://www.frontiersin.org/articles/10.3389/fpubh.2019.00056/full> (last visited August 19, 2020).

5. A. Usher, "COVID-19 Vaccines For All?" The Lancet 395, no. 10240 (2020): 1822-1823.

6. T.M. Bollyky, L.O. Gostin, and M.A. Hamburg, "The Equitable Distribution of COVID-19 Therapeutics and Vaccines," JAMA 323, no. 24 (2020): 24622463, doi:10.1001/jama.2020.6641.

7. L. O. Gostin and B. M. Meier, Foundations of Global Health छ Human Rights (Cambridge University Press, 2020).

8. P. Ball, "Anti-Vaccine Movement Could Undermine Efforts to End Coronavirus Pandemic, Researchers Warn," Nature 581 (2020): 251, available at <https:// www.nature.com/articles/d41586020-01423-4> (last visited August 19, 2020).

9. United Nations, Committee on Economic, Social and Cultural Rights, Substantive issues arising in the implementation of the International Covenant on Economic, Social and Cultural Rights: General Comment No. 14, Geneva: United Nations; 2000, U.N. Doc. E/C.12/2000/4.

10. United Nations. Special Rapporteur on the right of everyone to the enjoyment of the highest attainable standard of physical and mental health. Promotion and protection of human rights: human rights questions, including alternative approaches for improving the effective enjoyment of human rights and fundamental freedoms; Sept. 13, 2006, UN Doc. A/61/338.

11. United Nations,, Committee on Economic, Social and Cultural Rights, General comment No. 25 (2020) on science and economic, social and cultural rights (article 15 (1) (b), (2), (3) and (4) of the International Covenant on Economic, Social and Cultural Rights), Geneva: United Nations; 2020, U.N. Doc. $\mathrm{E} / \mathrm{C} .12 / \mathrm{GC} / 25$.

12. B. M. Meier, A.e Gelpi, M.M. Kavanagh, L. Forman, and J.J. Amon, "Employing Human Rights Frameworks to Realize Access to an HIV Cure," Journal of the International AIDS Society 18, no. 1 (2015): 1-7. 
13. United Nations, supra note 9, para. 31.

14. Id., para. 12 .

15. A. Usher, "COVID-19 Vaccines For All?" The Lancet 395, no. 10240 (2020): 1822-1823, available at <https://doi. org/10.1016/S0140-6736(20)31354-4> (last visited August 19, 2020).

16. J.C. Capretta, "The Fragile Vaccine Plan to Save the World: The Fast-Moving Partnership Between Governments and Philanthropy Merits U.S. Backing," The Bulwark, July 29, 2020, available at <https://thebulwark.com/the-fragile-vaccine-plan-to-save-the-world/> (last visited August 19, 2020).

17. World Health Organization, Pandemic Influenza Preparedness (PIP) Framework, available at <https://www.who. int/influenza/pip/en/> (last visited August 19, 2020).

18. "Global Governance for COVID-19 Vaccines," The Lancet 395 (2020): 1883.

19. R.P. Petchesky, Global Prescriptions: Gendering Health and Human Rights (Zed Books, 2006).

20. S. Huddart, M. Nash, A. Abdelrasoul, I. Bacearnicova, K. Bourque, and L. Mishra, "The Doha Declaration in Action: An Examination of Patent Law Flexibilities in the South African Acquired Immunodeficiency Syndrome Epidemic," Journal of Health Specialties 5 (2017): 30-34; M.D. Islam, W.A. Kaplan, D. Trachtenberg, et al.,
"Impacts of Intellectual Property Provisions in Trade Treaties on Access to Medicine in Low and Middle Income Countries: A Systematic Review," Global Health 15, no. 1 (2019): 88-102.

21. WHO Regional Office for South-East Asia, 23rd Meeting of Health Ministers of Countries of SEAR, "Access to Medicines and Vaccines: Implications of Intellectual Property Protection and Trade Agreements" SEA/HMM/ Meet23/5 (August 18, 2005).

22. "The Medicines Patent Pool," Unitaid, July 29, 2019), available at <https:// unitaid.org/project/medicines-patentpool> (last visited August 19, 2020).

23. K. Perehudoff and K. Sellin, "COVID19 Technology Access Pool (C-TAP): A Promising Human Rights Approach," Health and Human Rights Blog, available at <https://www.hhrjournal.org/ 2020/06/covid-19-technology-accesspool-c-tap-a-promising-human-rightsapproach/> (last visited August 19, 2020).

24. World Health Organisation, "COVID19 technology access pool," available at <https://www.who.int/emergencies/diseases/novel-coronavirus-2019/ global-research-on-novel-coronavirus2019-ncov/covid-19-technology-accesspool> (last visited August 19, 2020).

25. M. Moran, et al., "Registering New Drugs for Low-Income Countries: The
African Challenge," PLoS Medicine 8, no. 2 (2011): e1000411.

26. T.B. Ghedamu and B.M. Meier, "Assessing National Public Health Law to Prevent Infectious Disease Outbreaks: Immunization Law as a Basis for Global Health Security," Journal of Law, Medicine छீ Ethics 47, no. 3 (2019): 412-426.

27. N. Dellepiane and D. Wood, "TwentyFive Years of the WHO Vaccines Prequalification Programme (19872012): Lessons Learned and Future Perspectives," Vaccine 33, no. 1 (2015): 52-61.

28. World Health Organisation, "Prequalification," available at <https://www. who.int/rhem/prequalification/en/> (last visited August 19, 2020).

29. P. Duclos, "National Immunization Technical Advisory Groups (NITAGs) Guidance for Their Establishment and Strengthening, "Vaccine 28, Suppl. 1 (2010): A18-25. 